\title{
JOB STRESSORS AND JOB PERFORMANCE: MODELING OF MODERATING MEDIATION EFFECTS OF STRESS MINDSET
}

\author{
DOI: 10.17261/Pressacademia.2019.1020 \\ RJBM- V.6-ISS.1-2019(4)-p.35-45
}

Hsiao-Ling Chen ${ }^{1}$, Shih-Chieh Fang ${ }^{2}$

${ }^{1}$ National Cheng Kung University, Department of Business Administration, No.1, University Road, Tainan City 701, Taiwan (R.O.C). hsiaoochen@gmail.com, ORCID: 0000-0002-2459-127

${ }^{2}$ National Cheng Kung University, Department of Business Administration, No.1, University Road, Tainan City 701, Taiwan (R.O.C). fangsc@mail.ncku.edu.tw, ORCID: 0000-0001-5006-8677

To cite this document

Chen, H.-L., Fang, S.-C. (2019). Job stressors and job performance: Modeling of moderating mediation effects of stress mindset. Research Journal of Business and Management (RJBM), V.6(1), p.35-45.

Permemant link to this document: $\underline{\text { http://doi.org/10.17261/Pressacademia.2019.1020 }}$

Copyright: Published by PressAcademia and limited licenced re-use rights only.

\section{ABSTRACT}

Purpose - Job stress is widely concern to academic researcher and practitioner, work stress may affect employee attitudes and physical and mental health. We proposed that person's appraisal plays a critical role in the stress process, although the nature of job stress is sometimes to make people grow, sometimes make people shrink, but we believe that individual perception of stressors is the key factor affecting the followup behaviors. This study examines the moderated effect of stress mindset on the indirect relationship between job stressors and job performance mediated by job satisfaction. We integrated the transactional theory of stress and the concept of stress mindset, try to provide another explanation of boundary condition for the ambiguous results in the relation between stressors and job satisfaction.

Methodology - Research participants were general employees and their supervisors, data were collected from 487 employees from the different occupation in Taiwan, including trading company, restaurants, travel agency, bank, salesperson and staff of gas station and train station. Statistical analyses using SPSS and Mplus for model testing, the results show that there exists a moderated mediation effect. For measurement model of stress mindset, we conducted two-factor CFA to examine whether the eight items were loaded onto two factor. The result indicated that the data fit the two-factor model better than one-factor model. For structure model of research framework, the results supporting the independence of the six focal constructs, results indicated that the six-factor model fit the data better than the other models.

Findings - First, our results suggested that job sastisfaction mediated the positive relationship between challenge stressors and job performance, also mediated the negative relationship between hindrance stressors and job performance. Second, the positive relationship between challenge stressors and outcomes stronger when negative stress mindset is low, and negative relationship between hindrance stressors and outcomes weaker when positive stress mindset is high.

Conclusion - This study integrates the transactional theory of stress and the concept of stress mindset to investigate the moderating mediation model. Our findings reveal that individual's different stress mindset of stressors plays a critical moderating role during the process of pursuit working goal. Once individual hold a negative stress mindset, the positive mediation will become weaker; reversely, holding a positive stress mindset can help the negative mediation become weaker. Based on the research findings, implications and suggestions for theoretical and practical implication are discussed.

Keywords: Challenge stressors, hindrance stressors, negative stress mindset, positive stress mindset, job satisfaction. JEL Codes: D23, J28, M12 


\section{INTRODUCTION}

The issue of job stress is widely concern to academic researcher and practitioner. Kahn, Wolfe, Quinn, Snoek, and Rosenthal (1964) introduced the concept of stressors into organization and management research areas, organizational scholars have increasingly discussed stressors at workplace and developed stress management techniques. Mostly early studies stated that stress is harmful, and has a negative impact on organization and individuals, people must adopt effective strategies to prevent or reduce the incidence of stress (Atkinson, 2004; Bodenmann, Meuwly, Bradbury, Gmelch, \& Ledermann, 2010; McEwen \& Seeman, 1999; Schwabe \& Wolf, 2010). Cooper, Dewe, and O'Driscoll (2001) argued that work stress may affect employee attitudes and physical and mental health. However, prior studies mostly focused on the negative impact of stress but ignored the positive effect of stress may exist.

Some stressors in the workplace contain the elements of growth, can be opportunities for individuals to enhance performance, but some stressors erode employee's passion of the work, may hinder the effectiveness of work. Cavanaugh, Boswell, Roehling, and Boudreau (2000) followed inverted U-shape model (Selye, 1982) and transactional theory of stress (Lazarus \& Folkman, 1984), classified job stressors as challenge stressors and hindrance stressors. Challenge stressors have potential growth opportunities for individuals, can guide individual to invest effort into solving problems, result in positive consequences, such as higher job satisfaction (Cavanaugh et al., 2000; Podsakoff, LePine, \& LePine, 2007; Webster, Beehr, \& Christiansen, 2010); engagement (Crawford, LePine, \& Rich, 2010) and performance (LePine, Podsakoff, \& LePine, 2005); but lower turnover (Cavanaugh et al., 2000; Podsakoff et al., 2007). Conversely, hindrance stressors will make people stuck with job demand, reduce their work motivation and bring negative results (Podsakoff et al., 2007), such as higher turnover intention, withdraw behaviors (Cavanaugh et al., 2000; Podsakoff et al., 2007), and physical symptoms (Webster et al., 2010); but lower job satisfaction (Cavanaugh et al., 2000; Podsakoff et al., 2007; Webster et al., 2010), engagement (Crawford et al., 2010); motivation (LePine et al., 2005) and job performance (LePine et al., 2005; Pearsall, Ellis, \& Stein, 2009; Wallace, Edwards, Arnold, Frazier, \& Finch, 2009).

However, according to transactional theory of stress (Lazarus \& Folkman, 1984), person's appraisal plays a critical role in the stress process. Although the nature of job stress is sometimes to make people grow, sometimes make people shrink, but we believe that individual perception of stressors is the key factor affecting the follow-up behaviors. Existing research focused less on the moderating effect of individual mindset that affects individual behaviors. Therefore, we considered the boundary conditions in the relationship between stressors and outcomes by introduced the concept of stress mindset, refers as the extent to which one holds the belief that stress has enhancing or debilitating results (Crum, Salovey, \& Achor, 2013).

This study contributes to stress research in some ways. First, we integrate the transactional theory of stress and the concept of stress mindset, provide another viewpoint in stress issues. Second, we extend the concept of stress mindset proposed by Crum et al. (2013), which further divided into positive and negative stress mindset. Finally, we give another explanation of boundary condition for the ambiguous results in the relation between stressors and job satisfaction.

\section{LITERATURE REVIEW}

\subsection{Transactional Theory of Stress}

Lazarus and Folkman (1984) proposed transactional theory of stress, defined as an individual's psychological response to a critical situation and where the situation taxes or exceeds the individual's capacity or resources can offer, it is considered a product of the transaction between the individual and the environment. Central to the transactional theory of stress is the idea of cognitive appraisal, namely primary appraisal and secondary appraisal. Lazarus and Folkman (1984, 1986) using concepts from expectancy theory (Vroom, 1964), suggested that the initial appraisal process of stressors triggers specific emotional reactions and coping styles that in turn influence behaviors. Primary appraisal is to recognize that situation stressors are potential harm or benefit to the self. Secondary appraisal is then concerned with identifying the appropriate response or coping ways to the specific stressors.

\subsection{Challenge and Hindrance Stressors}

Cavanaugh et al. (2000) followed Selye (1982) and Lazarus and Folkman's $(1984,1986)$ work, suggested that job stressors have negative and positive effects on work outcomes. They classified work stressors into "challenge" and "hindrance" stressors. Challenge stressors were defined as "work-related demands or circumstances that, although potentially stressful, have associated potential gains for individuals", such as workload, time pressure, job responsibility, and job complexity. Hindrance stressors were defined as "work-related demands or circumstances that tend to constrain or interfere with an individual's work 
achievement and that do not tend to be associated with potential gains for the individual", for instances, role ambiguity, role conflict, hassles, red tape, organizational politics, and job insecurity (Cavanaugh et al., 2000, p. 68).

Existing studies shown that challenge stressors are positively related to job attitude, such as job satisfaction (Cavanaugh et al., 2000; Podsakoff et al., 2007; Webster et al., 2010), loyalty (Boswell, Olson-Buchanan, \& LePine, 2004), organizational commitment (Podsakoff et al., 2007), engagement (Crawford et al., 2010); cognition, such as motivation (LePine et al., 2005), self-efficacy (Webster et al., 2010), organizational justice (Zhang, LePine, Buckman, \& Wei, 2014); and behaviors, such as performance (LePine et al., 2005), role-based performance (task performance, citizenship performance, and customer service performance; Wallace et al., 2009). But, negative effects on job attitude, such as intention to quit (Boswell et al., 2004), turnover intention (Podsakoff et al., 2007); and behaviors, such as job search (Boswell et al., 2004; Cavanaugh et al., 2000), turnover (Cavanaugh et al., 2000; Podsakoff et al., 2007), and work withdrawal behavior (Boswell et al., 2004).

On the other hand, hindrance stressors are positively related to job attitude, such as intention to quit (Boswell et al., 2004), turnover intention (Podsakoff et al., 2007), psychological withdrawal (Pearsall et al., 2009); and behaviors, such as job search (Boswell et al., 2004; Cavanaugh et al., 2000), turnover (Cavanaugh et al., 2000; Podsakoff et al., 2007), withdraw behaviors (Podsakoff et al., 2007), physical symptoms (Webster et al., 2010). Hindrance stressors also have negative effects on job attitude, such as job satisfaction (Cavanaugh et al., 2000; Podsakoff et al., 2007; Webster et al., 2010), loyalty (Boswell et al., 2004), organizational commitment (Podsakoff et al., 2007), engagement (Crawford et al., 2010); cognition, such as motivation (LePine et al., 2005), self-efficacy (Webster et al., 2010), organizational justice (Zhang et al., 2014); and behaviors, such as performance (LePine et al., 2005), role-based performance (task performance, citizenship performance, and customer service performance; Wallace et al., 2009), and team performance (Pearsall et al., 2009).

Job satisfaction refers to a psychological state resulting from the evaluation of one's job experiences (Locke, 1976). Based on transactional theory of stress and challenge-hindrance framework, challenge stressors have potential gains for individuals, it should be positively associated with attitudinal and behavioral outcomes. Conversely, hindrance stressors have potential for harm or failure, it is likely to be negatively associated with attitudinal and behavioral outcomes (LePine et al., 2005; Webster et al., 2010; Webster, Beehr, \& Love, 2011). According to Lazarus and Folkman (1984), individual will activate initial appraisal process when they face stressors and trigger positive or negative emotional reactions in turn influence behaviors. Challenge stressors provide potential growth opportunities for employees, active employee's enthusiasm for work and positively affect job satisfaction. Conversely, hindrance stressors tend to interfere with employee's work achievement and negatively affect job satisfaction. Prior studies supported that challenge stressors will positively but hindrance stressors will negatively affect job satisfaction (Podsakoff et al., 2007; Webster et al., 2010) and both challenge stressors and hindrance stressors were positively effect on job performance (LePine et al., 2005). We argued that job satisfaction will mediate the effects of stressors on job performance (Fried, Shirom, Gilboa, \& Cooper, 2008), and employees who are satisfied with their jobs will enhance their performance in jobs, the recent study also found the similar evidence (Nasir, Khan, \& Nasir, 2017). Thus, we proposed hypothesis 1 and 2 as follow.

Hypothesis 1: Job satisfaction mediates the positive relationship between challenge stressors and job performance.

Hypothesis 2: Job satisfaction mediates the negative relationship between hindrance stressors and job performance.

\subsection{Stress Mindset}

"Mindset" defines as a mental frame or lens of what we selectively organize and encode information, and guide individual's corresponding actions and responses by a unique way of understanding (Dweck, 2008). Crum et al. (2013) bring the concept of mindset into the field of stress, stress mindset is the extent to which an individual holds the conviction that stress has enhancing or debilitating. They suggested that change one's stress mindset can improve people's response to stress. Specifically, if individual holds a stress-is-enhancing mindset, the primary motivation is to accept and utilize stress toward achieving their goals, brings positive consequence. On the other hand, if individual holds a stress-is-debilitating mindset, the primary motivation is to avoid or manage the stress to prevent negative or debilitating outcomes.

Although two types of stressors affect opposite consequences, existing research found that both challenge and hindrance stressors are positively related to psychological strain (anxiety and emotional exhaustion; Boswell et al., 2004), exhaustion (LePine, LePine, \& Jackson, 2004), strain (LePine et al., 2005; Podsakoff et al., 2007), anxiety (Rodell \& Judge, 2009), frustration (Webster et al., 2010), burnout (Crawford et al., 2010). According to review paper of Podsakoff et al. (2007), we agree that both challenge stressors and hindrance stressors will increase psychological strain and strain will negatively lead to job satisfaction. However, the mediator variable for strain does not explain that how challenge stressors positively affects job satisfaction and 
hindrance stressors is negative effect on job satisfaction. We believe that individual's perception of stressors may play an important moderating variable.

The stress mindset measure is developed by Crum et al. (2013), they treated stress-is-enhancing and stress-is-debilitating mindset as the continuum, thus higher score of scale means one's holds stress-is-enhancing, and lower score means mindset of stress-is-debilitating. However, we think that stress mindset should be two independent factors, hence we separated their measure into positive and negative stress mindset. The individual holds positive stress mindset can bring benefit results, but negative stress mindset will bring damage results. We argue that even though challenge stressors can bring positive outcomes, but if individual hold negative stress mindset, the positive relationship will be debilitating. Even stressors were recognized as promoting growth, negative perception of stressors will damage employee's job satisfaction and the potential successful performance. Reversely, even hindrance stressors will constrain individuals' development and performance, once individual can hold positive stress mindset, at least employee will try to solve the problem. If they think there still have chance to invest effort, depends on our appraisal of how we perceived stressors is helpful or harmful. This can reduce the negative relationship between hindrance stressors and job satisfaction and performance. Thus, we proposed hypothesis 3 and 4 as follow.

Hypothesis 3: Negative stress mindset (NSM) will moderate the positive indirect effect of challenge stressors and job performance mediated by job satisfaction. When NSM is high, the positive indirect effect weakens; when NSM is low, the positive indirect effect is stronger.

Hypothesis 4: Positive stress mindset (PSM) will moderate the negative indirect effect of hindrance stressors and job performance mediated by job satisfaction. When PSM is high, the negative indirect effect weakens; when PSM is low, the negative indirect effect is stronger.

Figure 1: Research Model

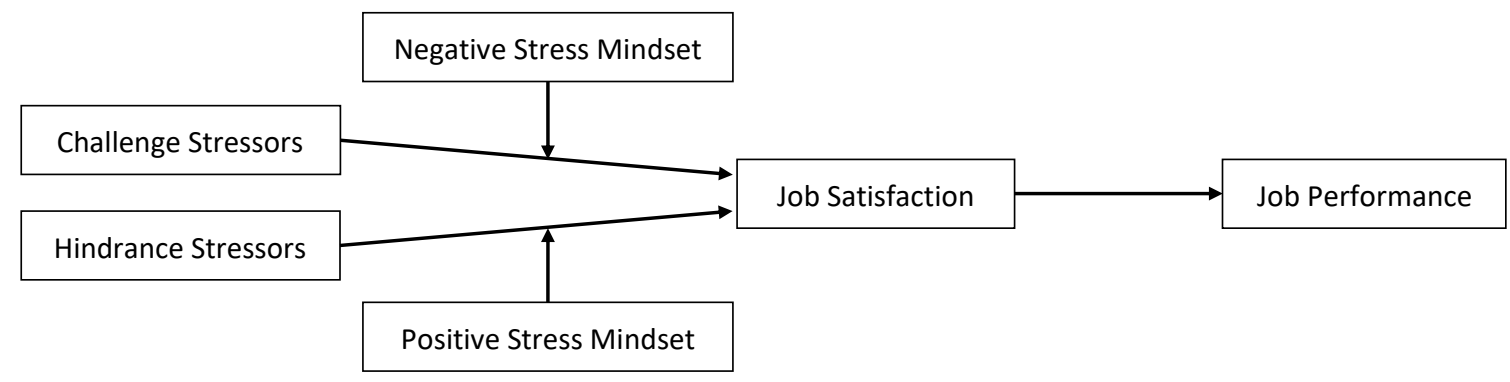

\section{DATA AND METHODOLOGY}

\subsection{Sample and Procedure}

The research participants were general employees and their supervisors. Randomized sampling was used to 530 employees from different occupation, including trading company, restaurants, travel agency, bank, salesperson and staff of gas station and train station in Taiwan. After uncompleted questionnaires were excluded, a final sample was 487 questionnaires was used for data analyses. The employees' demographics showed that $57.6 \%$ were females, with an average age of 26.10 years and average work tenure of 4.94 years. Most were single (85.2\%) with college education level $(76.3 \%)$.

\subsection{Measure}

Challenge and hindrance stressors. Cavanaugh et al. (2000) challenge-hindrance stressors scale was used in our study. There are 6 items measured challenge stressors, a sample item was "The amount of time I spend at work." The Cronbach's alpha coefficient was 0.81 . On the other hand, 5 items measured hindrance stressors, a sample item was "The lack of job security I have." The Cronbach's alpha coefficient was 0.73 .

Positive and negative stress mindset. We measured stress mindset using the stress mindset measure-general (SMM-G) 8-item scale of Crum et al. (2013), but we treated original four of eight positive items as positive stress mindset and the other four inverted items as negative stress mindset. A sample item of positive stress mindset was "Experiencing stress facilitates my 
learning and growth." The Cronbach's alpha coefficient was 0.69. A sample item of negative stress mindset was "The effects of stress are negative and should be avoided." The Cronbach's alpha coefficient was 0.63.

Job satisfaction. The 3-item Michigan Organizational Assessment Questionnaire of Camman, Fichman, Jenkins, and Klesh (1979) was used. A sample item was “Overall, I am satisfied with my job." The Cronbach's alpha coefficient was 0.78.

Job performance. The 5-item job performance scale developed by Viswesvaran, Ones, and Schmidt (1996) was used. A sample item was "My working quality is high." The Cronbach's alpha coefficient was 0.70 . All variables in this study followed responses ranging from 1 (strongly disagree) to 5 (strongly agree).

Control variable. We included the demography control variables, gender, age, tenure, marriage and education.

\subsection{Confirmatory Factor Analysis}

First, stress mindset was originally loaded onto one factor (Crum et al., 2013), we conducted two-factor CFA to examine whether the eight items were loaded onto two factor. The result indicated that the data fit the two-factor model (chi-square $=169.910$, $\mathrm{df}=19 ; \mathrm{CFI}=0.819 ; \mathrm{NNFI}=0.733 ; \mathrm{RMSEA}=0.128 ; \mathrm{SRMR}=0.067$ ) better than one-factor model $($ chi-square $=528.029, \mathrm{df}=20$; $\mathrm{CFI}=0.390 ; \mathrm{NNFI}=0.147 ; \mathrm{RMSEA}=0.228 ; \mathrm{SRMR}=0.144$ ).

Second, we examined the validity of our measures by performing a confirmatory factor analysis. Owing to the limited sample size relative to the large number of parameters estimated in the model can be difficult to confirm (Floyd \& Widaman, 1995), we created parcels of items (including two or three items for each variable except stress mindset) for analyses. Each parcel was constrained to load onto the latent construct without any error covariance. Table 1 presents a description of the models and their results. Supporting the independence of the six focal constructs, results indicated that the six-factor model (chi-square $=$ 691.694, $\mathrm{df}=120 ; \mathrm{CFI}=0.838 ; \mathrm{NNFI}=0.793 ; \mathrm{RMSEA}=0.097 ; \mathrm{SRMR}=0.091$ ) fit the data better than the other models.

Table 1: Confirmatory Factor Analysis of Nested Models

\begin{tabular}{|c|c|c|c|c|c|c|c|c|}
\hline Model & $x^{2}$ & df & $\Delta \times 2$ & $\Delta$ df & CFI & NNFI & RMSEA & SRMR \\
\hline Six-factor model & $691.694^{* * *}$ & 120 & - & - & .838 & .793 & .097 & .091 \\
\hline Five-factor model & $1052.628^{* * *}$ & 125 & 360.934 & 5 & .736 & .677 & .122 & .132 \\
\hline Four-factor model & $1682.967^{* * *}$ & 129 & 630.339 & 4 & .558 & .476 & .155 & .148 \\
\hline Three-factor model & $1943.792^{* * *}$ & 132 & 260.825 & 3 & .485 & .403 & .165 & .159 \\
\hline Two-factor model & $2242.640^{* * *}$ & 134 & 298.848 & 2 & .401 & .316 & .177 & .181 \\
\hline
\end{tabular}

${ }^{*} p<0.05,{ }^{* *} p<0.01,{ }^{* * *} p<0.001$

Note: CS = Challenge Stressors; HS = Hindrance Stressors; PSM = Positive Stress Mindset; NSM = Negative Stress Mindset; JS = Job Satisfaction; JP = Job Performance. Two-factor model (CS+HS+PSM+NSM, JS+JP); Three-factor model (CS+HS+PSM+NSM, JS, JP); Four-factor model (CS+HS, $P S M+N S M, J S$, JP); Five-factor model (CS, HS, PSM+NSM, JS, JP); Six-factor model (CS, HS, PSM, NSM, JS, JP).

\section{FINDINGS}

Mean, standard deviation, and correlation of studied variables are shown in Table 2. The correlations for most variables were positive and significant. Except the job satisfaction was negatively correlated to hindrance stressors and negative stress mindset. Besides, there is no correlation between hindrance stressors and negative stress mindset, also challenge stressors and positive stress mindset.

Table 3 shows the results of the hierarchical mediation regression analysis for job performance that were used to test hypotheses 1 and 2. Model 1-2 in Table 3 shows that challenge stressors positively $(\beta=0.22, \mathrm{SE}=0.05, p<0.001)$ and hindrance stressors negatively $(\beta=-0.44$, SE $=0.04, p<0.001)$ predicted to job satisfaction. Model $2-3$ shows that job satisfaction significantly mediated the relationship between challenge and hindrance stressors and job performance $(\beta=0.19, \mathrm{SE}=0.03, \mathrm{p}<$ 0.001); therefore, hypothesis 1 and 2 were supported. 
Table 2: Means, Standard Deviations, and Correlations among All Variables Studied

\begin{tabular}{|c|c|c|c|c|c|c|c|c|c|c|c|c|c|}
\hline Variables & Means & $S D$ & 1 & 2 & 3 & 4 & 5 & 6 & 7 & 8 & 9 & 10 & 11 \\
\hline 1.Gender & 1.58 & .50 & - & & & & & & & & & & \\
\hline 2.Age & 26.03 & 10.71 & .03 & - & & & & & & & & & \\
\hline 3.Tenure & 4.94 & 7.87 & .05 & $.88^{* * *}$ & - & & & & & & & & \\
\hline 4.Marriage & 1.15 & .36 & .06 & $.81^{* * *}$ & $.74^{* * *}$ & - & & & & & & & \\
\hline 5.Education & 2.84 & .53 & .09 & .02 & -.09 & -.08 & - & & & & & & \\
\hline 6.CS & 3.60 & .62 & .02 & $.21^{* * *}$ & $.16^{* * *}$ & $.16^{* * *}$ & $.14^{* *}$ & $(.81)$ & & & & & \\
\hline 7.HS & 2.72 & .68 & .00 & .04 & .03 & .05 & .02 & $.22^{* * *}$ & $(.73)$ & & & & \\
\hline 8.PSM & 3.62 & .56 & -.05 & -.08 & $-.09^{*}$ & $-.11^{*}$ & .05 & $.25^{* * *}$ & .01 & (.69) & & & \\
\hline 9.NSM & 3.06 & .68 & -.04 & .03 & .02 & .03 & -.08 & .06 & $.32^{* * *}$ & $.13^{* *}$ & $(.63)$ & & \\
\hline 10.JS & 3.64 & .70 & -.01 & .07 & .06 & .08 & $.10^{*}$ & $.11^{*}$ & $-.38^{* * *}$ & $.37^{* * *}$ & $-.19^{* * *}$ & (.78) & \\
\hline 11.JP & 3.57 & .54 & -.01 & $.15^{* *}$ & $.13^{* *}$ & .08 & $.12^{* *}$ & $.56^{* * *}$ & $.12^{* *}$ & $.38^{* * *}$ & $.18^{* * *}$ & $.27^{* * *}$ & $(.70)$ \\
\hline
\end{tabular}

Note: $N=487$. Reliabilities are reported in parentheses. $C S=$ Challenge Stressors; HS = Hindrance Stressors; PSM = Positive Stress Mindset; NSM = Negative Stress Mindset; JS = Job Satisfaction; JP = Job Performance.

Table 3: Results of Mediation Regression Analysis

\begin{tabular}{|c|c|c|c|c|c|}
\hline & & & & & \\
\hline & Job Sa & ffaction & & lob Performan & \\
\hline & Model 1-1 & Model 1-2 & Model 2-1 & Model 2-2 & Model 2-3 \\
\hline Control Variable & & & & & \\
\hline Gender & $-.05(.06)$ & $-.05(.06)$ & $-.03(.05)$ & $-.03(.04)$ & $-.02(.04)$ \\
\hline Age & $-.00(.01)$ & $-.00(.01)$ & $.01(.01)$ & $.00(.01)$ & $.00(.01)$ \\
\hline Tenure & $.01(.01)$ & $.00(.01)$ & $.00(.01)$ & $.01(.01)$ & $.01(.01)$ \\
\hline Marriage & $.16(.16)$ & $.21(.14)$ & $-.10(.12)$ & $-.10(.10)$ & $-.14(.10)$ \\
\hline Education & $.16(.06)^{* *}$ & $.14(.06)^{*}$ & $.11(.05)^{*}$ & $.04(.04)$ & $.02(.04)$ \\
\hline Independent Variable & & & & & \\
\hline Challenge Stressors & & $.22(.05)^{* * *}$ & & $.47(.03)^{* * *}$ & $.43(.03)^{* * *}$ \\
\hline Hindrance Stressors & & $-.44(.04)^{* * *}$ & & $-.01(.03)$ & $.07(.03)^{*}$ \\
\hline Mediator & & & & & \\
\hline Job Satisfaction & & & & & $.19(.03)^{* * *}$ \\
\hline $\mathrm{R}^{2}$ & .02 & .20 & .04 & .32 & .37 \\
\hline $\mathrm{F}$ & 1.98 & $17.40^{* * *}$ & $3.80^{* *}$ & $31.97^{* * *}$ & $34.73^{* * *}$ \\
\hline$\Delta \mathrm{R}^{2}$ & & .18 & & .28 & .05 \\
\hline$\Delta \mathrm{F}$ & & $54.84^{* * *}$ & & $98.54^{* * *}$ & $37.18^{* * *}$ \\
\hline
\end{tabular}

Note: The regression coefficient is unstandardized coefficient and stander error is reported in parentheses.

Regarding hypothesis 3 and 4, we expected NSM would have a moderating effect on the first stage of hypothesis 1 and PSM would have a moderating effect on the first stage of hypothesis 2 . The results of hierarchical moderation regression analysis were shown in Table 4. Model 4 in Table 4 shows that the interaction term of challenge stressors and NSM has a significant negative effect on job satisfaction $(\beta=-0.07, \mathrm{SE}=0.02, p<0.01)$; and another interaction term of hindrance stressors and PSM has a significant positive effect on job satisfaction $(\beta=0.06, \mathrm{SE}=0.02, \mathrm{p}<0.01)$. We also conducted a hierarchical moderating mediation regression analysis by using Mplus 7.0, the result as shown in Table 5.

First, Table 5 shows the interaction term of challenge stressors and NSM has a significant negative moderated effect on job satisfaction $(\beta=-0.18, \mathrm{SE}=0.06, p<0.01)$. We have plotted this interaction at conditional values of NSM ( 1 SD above and below the mean) in Figure 2. This graph indicates that the positive indirect relationship between challenge stressors and job performance mediated by job satisfaction is stronger when NSM is low, therefore, hypothesis 3 was supported. On the other 
hand, Table 5 also shows another interaction term of hindrance stressors and PSM has a significant positive moderated effect on job satisfaction $(\beta=0.16, \mathrm{SE}=0.07, \mathrm{p}<0.05)$. We also plotted this interaction at conditional values of PSM (1 SD above and below the mean) in Figure 3. This graph indicates that the negative indirect relationship between hindrance stressors and job performance mediated by job satisfaction is stronger when PSM is low, therefore, hypothesis 4 was supported.

Second, to further determine whether NSM and PSM weakened the indirect relationship as predicted by Hypothesis 1 and 2, we considered an alternative moderated mediation model, including the first stage, second stage, direct, indirect, and total effects of the moderator (NSM and PSM). The NSM results shown in Table 6 indicate a pattern consistent with our prediction, with significant effects in the first stage effect (diffidence $\beta=0.240, \mathrm{SE}=0.078, p<0.01$ ); therefore, hypothesis 3 was supported. The PSM results shown in Table 7, also consistent with our prediction, with significant effects in the first stage effect (diffidence $\beta=-$ $0.174, \mathrm{SE}=0.073, \mathrm{p}<0.05)$; therefore, hypothesis 4 was supported.

\section{CONCLUSION AND DISCUSSIONS}

This study integrates the transactional theory of stress and the concept of stress mindset to investigate the moderating mediation model. First, our results suggested that job satisfaction mediated the positive relationship between challenge stressors and job performance, also mediated the negative relationship between hindrance stressors and job performance. Second, we introduce concept of stress mindset proposed by Crum et al. (2013), and further divided into positive and negative stress mindset. Our findings reveal that individual's different stress mindset of stressors plays a critical moderating role during the process of pursuit working goal. Once individual hold a negative stress mindset, the positive mediation will become weaker; reversely, holding a positive stress mindset can help the negative mediation become weaker.

\section{Table 4: Results of Moderation Regression Analysis}

\begin{tabular}{|c|c|c|c|c|}
\hline \multirow[b]{2}{*}{ Control Variable } & \multicolumn{4}{|c|}{ Job Satisfaction } \\
\hline & Model 1 & Model 2 & Model 3 & Model 4 \\
\hline Gender & $-.05(.06)$ & $-.05(.06)$ & $-.04(.05)$ & $-.04(.05)$ \\
\hline Age & $-.00(.01)$ & $-.00(.01)$ & $-.00(.01)$ & $-.00(.01)$ \\
\hline Tenure & $.01(.01)$ & $.00(.01)$ & $.00(.01)$ & $.00(.01)$ \\
\hline Marriage & $.16(.16)$ & $.21(.14)$ & $.30(.13)^{*}$ & $.32(.13)^{*}$ \\
\hline Education & $.16(.06)^{* *}$ & $.14(.06)^{*}$ & $.12(.05)^{*}$ & $.14(.05)^{* *}$ \\
\hline \multicolumn{5}{|c|}{ Independent Variable } \\
\hline CS & & $.13(.03)^{* * *}$ & $.05(.03)^{\dagger}$ & $.05(.03)^{\dagger}$ \\
\hline $\mathrm{HS}$ & & $-.30(.03)^{* * *}$ & $-.26(.03)^{* * *}$ & $-.25(.03)^{* * *}$ \\
\hline \multicolumn{5}{|l|}{ Moderator } \\
\hline PSM & & & $.28(.03)^{* * *}$ & $.28(.03)^{* * *}$ \\
\hline NSM & & & $-.09(.03)^{* *}$ & $-.08(.03)^{* *}$ \\
\hline \multicolumn{5}{|l|}{ Interaction } \\
\hline CS*PSM & & & & $.12(.02)$ \\
\hline CS*NSM & & & & $-.07(.02)^{* *}$ \\
\hline HS*PSM & & & & $.06(.02)^{* *}$ \\
\hline HS*NSM & & & & $-.02(.02)$ \\
\hline$R^{2}$ & .02 & .20 & .34 & .36 \\
\hline $\mathrm{F}$ & 1.98 & $17.40^{* * *}$ & $27.53^{* * *}$ & $20.81^{* * *}$ \\
\hline$\Delta \mathrm{R}^{2}$ & & .18 & .14 & .02 \\
\hline$\Delta \mathrm{F}$ & & $54.84^{* * *}$ & $50.43^{* * *}$ & $4.09^{* *}$ \\
\hline
\end{tabular}

${ }^{+} p<0.1,{ }^{*} p<0.05,{ }^{* *} p<0.01,{ }^{* * *} p<0.001$

Note: $C S=$ Challenge Stressors; $H S=$ Hindrance Stressors; $P S M=$ Positive Stress Mindset; NSM = Negative Stress Mindset. The regression coefficient is unstandardized coefficient and stander error is reported in parentheses.

\subsection{Theoretical Implication}

First, existing studies lack empirical evidence to link the relationship between challenge-hindrance framework, job satisfaction and job performance, and our study fills this research gap. According to the transactional theory of stress Lazarus and Folkman 
(1984, 1986), individual will appraise the stressors they encounter, challenge stressors can trigger positive emotion and lead to positive outcomes; hindrance stressors will trigger negative emotion and result in bad outcomes. Our findings suggested that challenge stressors can positive affect job satisfaction and enhance job performance, but hindrance stressors will damage employee's job satisfaction and reduce job performance, which extends the existing studies (Fried et al., 2008; LePine et al., 2005; Podsakoff et al., 2007; Webster et al., 2010).

Second, Crum et al. (2013) bring concept of mindset into stress issue, they suggested that one's mindset tend to stress-isenhancing will lead to positive consequence; conversely, one's mindset tend to stress-is-debilitating will lead to negative outcomes. We agree with Crum et al. (2013), and argue that different stress mindset can result in different behaviors. However, we don't agree with Crum et al. (2013) the methodological way they employed which treated stress mindset as a spectrum, the degree of stress-is-enhancing or stress-is-debilitating. We divided stress mindset scale into positive and negative two factors, and the result of the confirmatory factor analysis also supports our idea. Therefore, we refined Crum et al. (2013) stress mindset measures, provide future researchers with another option.

Furthermore, we give an explanation for the ambiguous results in the relation between two types of stressors and job satisfaction (Podsakoff et al., 2007). Result shows that stress mindset is a boundary condition that moderates the relationship between stressors and job satisfaction. Even challenge stressors were recognized as "good" stress and can lead to beneficial consequence, but if one's hold negative stress mindset, this positive relationship will be impaired. Conversely, hindrance stressors was treated as "bad" stress and brings damage outcomes, but if employee can hold positive stress mindset, this negative relationship will be repaired.

Table 5: Moderated Mediation Model Results

\begin{tabular}{|c|c|c|}
\hline & Job Satisfaction & Job Performance \\
\hline Intercepts & $-.62(.23)^{* *}$ & $3.56(.14)^{* * *}$ \\
\hline \multicolumn{3}{|c|}{ Control variables } \\
\hline Gender & $-.04(.05)$ & $-.01(.04)$ \\
\hline Age & $-.00(.01)$ & $.00(.01)$ \\
\hline Tenure & $.00(.01)$ & $.01(.01)$ \\
\hline Marriage & $.32(.16)^{*}$ & $-.09(.09)$ \\
\hline Education & $.14(.06)^{*}$ & $.03(.04)$ \\
\hline \multicolumn{3}{|c|}{ Independent variables } \\
\hline CS & $.08(.05)$ & $.38(.04)^{* * *}$ \\
\hline $\mathrm{HS}$ & $-.37(.05)^{* * *}$ & $.01(.04)$ \\
\hline \multicolumn{3}{|l|}{ Mediator } \\
\hline JS & & $.15(.05)^{* *}$ \\
\hline \multicolumn{3}{|l|}{ Moderator } \\
\hline PSM & $.50(.06)^{* *}$ & $.15(.05)^{* *}$ \\
\hline NSM & $-.12(.05)^{*}$ & $.14(.04)^{* * *}$ \\
\hline \multicolumn{3}{|l|}{ Interaction } \\
\hline CS*PSM & $.03(.07)$ & $.01(.08)$ \\
\hline CS*NSM & $-.18(.06)^{* *}$ & $-.02(.05)$ \\
\hline HS*PSM & $.16(.07)^{*}$ & $-.01(.09)$ \\
\hline HS*NSM & $-.04(.05)$ & $.01(.05)$ \\
\hline JS*PSM & & $-.02(.08)$ \\
\hline JS*NSM & & $-.12(.07)^{\dagger}$ \\
\hline
\end{tabular}

Note: $\mathrm{CS}=$ Challenge Stressors; HS = Hindrance Stressors; JS = Job Satisfaction; PSM = Positive Stress Mindset; NSM = Negative Stress Mindset. The estimate is unstandardized coefficient and stander error is reported in parentheses. 
Figure 1: Negative stress mindset (NSM) moderates the mediation effect of job satisfaction between challenge stressors (CS) and job performance.

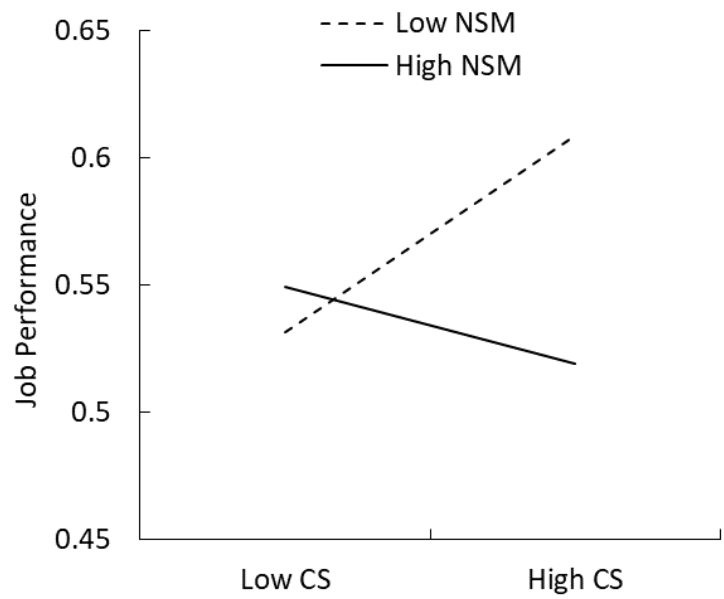

Figure 2: Positive stress mindset (PSM) moderates the mediation effect of job satisfaction between hindrance stressors (HS) and job performance.

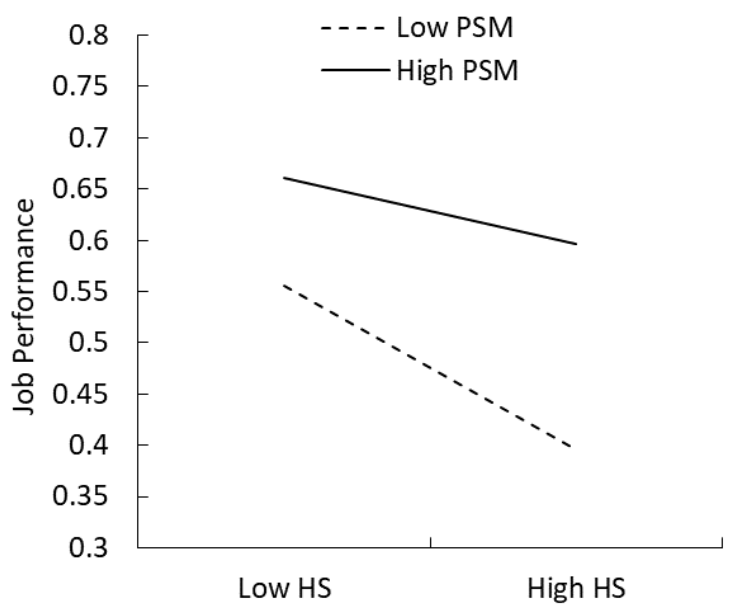

Table 6: Overview of Significant Moderated Mediation Effects for Negative Stress Mindset

\begin{tabular}{rccccc}
\hline & First Stage Effect & Second Stage Effect & Direct Effect & Indirect Effect & Total Effect \\
\hline Low_NSM (-1 SD) & $.197(.053)^{* * *}$ & $.232(.082)^{* *}$ & $.391(.055)^{* * *}$ & $.046(.021)^{*}$ & $.437(.052)^{* * *}$ \\
High_NSM (+1 SD) & $-.043(.074)$ & $.073(.049)$ & $.366(.053)^{* * *}$ & $-.003(.007)$ & $.363(.054)^{* * *}$ \\
Diffidence & $.240(.078)^{* *}$ & $.159(.093)^{+}$ & $.025(.072)$ & $.049(.020)^{*}$ & $.074(.069)$ \\
\hline
\end{tabular}

${ }^{+} p<0.1,{ }^{*} p<0.05,{ }^{* *} p<0.01,{ }^{* * *} p<0.001$

Note: $N S M=$ Negative Stress Mindset $(S D=.67780)$. Standard errors are reported in parentheses.

Table 7: Overview of Significant Moderated Mediation Effects for Positive Stress Mindset

\begin{tabular}{rccccc}
\hline & First Stage Effect & Second Stage Effect & Direct Effect & Indirect Effect & Total Effect \\
\hline Low_PSM (-1 SD) & $-.456(.070)^{* * *}$ & $.162(.068)^{*}$ & $.021(.076)$ & $-.074(.030)^{*}$ & $-.053(.065)$ \\
High_PSM (+1 SD) & $-.282(.055)^{* * *}$ & $.143(.067)^{*}$ & $.008(.051)$ & $-.040(.018)^{*}$ & $-.032(.047)$ \\
Diffidence & $-.174(.073)^{*}$ & $.019(.093)$ & $.013(.101)$ & $-.034(.034)$ & $-.021(.083)$ \\
\hline
\end{tabular}

${ }^{*} p<0.05,{ }^{* *} p<0.01,{ }^{* * *} p<0.001$

Note: $P S M=$ Positive Stress Mindset $(S D=.56233)$. Standard errors are reported in parentheses.

\subsection{Empirical Implication}

Our findings suggested that job satisfaction mediated the relationship between challenge/hindrance stressors and job performance. In practice, the organization should try to provide employee more growth and development opportunities for the job, such as setting timeliness of task completion, increase job responsibility or complexity of task, these challenge stressors can make working situation become more challenging. This paper also presents that stress mindset can affect individuals' attitudes and consequent behaviors. Consequently, organization could assist employee to establish positive mindset or develop positive thinking by organize learning activity or set up psychological counseling units to help employees rethink the stressors they faced.

\subsection{Limitations and Suggestion for Future Research}

There are still some research limitations in this study. First, our research variables are derived from employee self-reporting, may lead to common methods variance concerns, especially job performance may have inflation effect. We suggest future study should use supervisor-employee dyad questionnaire to exclude common sources concerns. Second, we divided stress mindset scale into two factors without pilot study to ensure the reliability of the scale. Although the confirmatory factor analysis shows 
two-factor model is preferred, but we recommended the follow-up studies should be categorized in a more rigorous manner. Third, our sample only for Taiwanese employees, the results may not be enough to generalize to other countries, suggesting that future research should increase the research sample to increase the external validity.

\section{REFERENCES}

Atkinson, W. (2004). Stress: Risk management's most serious challenge? Risk Management, 51(6), 20-26.

Bodenmann, G., Meuwly, N., Bradbury, T. N., Gmelch, S., Ledermann, T. (2010). Stress, anger, and verbal aggression in intimate relationships: Moderating effects of individual and dyadic coping. Journal of Social and Personal Relationships, 27(3), 408-424.

Boswell, W. R., Olson-Buchanan, J. B., LePine, M. A. (2004). Relations between stress and work outcomes: The role of felt challenge, job control, and psychological strain. Journal of Vocational Behavior, 64(1), 165-181. doi:10.1016/S0001-8791(03)00049-6

Camman, C., Fichman, M., Jenkins, D., Klesh, J. (1979). The Michigan organizational assessment questionnaire. University of Michigan. Ann Arbor, MI.

Cavanaugh, M. A., Boswell, W. R., Roehling, M. V., Boudreau, J. W. (2000). An empirical examination of self-reported work stress among U.S. managers. Journal of Applied Psychology, 85(1), 65-74. doi:10.1037//0021-9010.85.1.65

Cooper, C. L., Dewe, P., O'Driscoll, M. P. (2001). Organizational stress: A review and critique of theory, research and applications: SAGE Publications, Inc.

Crawford, E. R., LePine, J. A., Rich, B. L. (2010). Linking job demands and resources to employee engagement and burnout: A theoretical extension and meta-analytic test. Journal of Applied Psychology, 95(5), 834-848.

Crum, A. J., Salovey, P., Achor, S. (2013). Rethinking stress: The role of mindsets in determining the stress response. Journal of Personality and Social Psychology, 104(4), 716-733. doi:10.1037/a0031201

Dweck, C. S. (2008). Can personality be changed? The role of beliefs in personality and change. Current Directions in Psychological Science, 17(6), 391-394. doi:10.1111/j.1467-8721.2008.00612.x

Floyd, F. J., Widaman, K. F. (1995). Factor analysis in the development and refinement of clinical assessment instruments. Psychological Assessment, 7(3), 286-299.

Fried, Y., Shirom, A., Gilboa, S., Cooper, C. L. (2008). The mediating effects of job satisfaction and propensity to leave on role stress-job performance relationships: Combining meta-analysis and structural equation modeling. International Journal of Stress Management, 15(4), 305328.

Kahn, R. L., Wolfe, D. M., Quinn, R. P., Snoek, J. D., Rosenthal, R. A. (1964). Organizational stress: Studies in role conflict and ambiguity. Oxford, England: John Wiley.

Lazarus, R. S., Folkman, S. (1984). Stress, appraisal, and coping. New York: Springer Publishing Company.

Lazarus, R. S., Folkman, S. (1986). Cognitive theories of stress and the issue of circularity. In M. H. Appley \& R. Trumbull (Eds.), Dynamics of Stress: Physiological, Psychological and Social Perspectives (pp. 63-80). Boston, MA: Springer US.

LePine, J. A., LePine, M. A., Jackson, C. L. (2004). Challenge and hindrance stress: Relationships with exhaustion, motivation to learn, and learning performance. Journal of Applied Psychology, 89(5), 883-891. doi:10.1037/0021-9010.89.5.883

LePine, J. A., Podsakoff, N. P., LePine, M. A. (2005). A meta-analytic test of the challenge stressor-hindrance stressor framework: An explanation for inconsistent relationships among stressors and performance. Academy of Management Journal, 48(5), 764-775. doi:10.5465/amj.2005.18803921

Locke, E. A. (1976). The nature and causes of job satisfaction. In M. D. Dunnette (Ed.), Handbook of industrial and organizational psychology (pp. 1297-1343). Chicago, IL: Rand McNally.

McEwen, B. S., Seeman, T. (1999). Protective and damaging effects of mediators of stress: Elaborating and testing the concepts of allostasis and allostatic load. Annals of the New York Academy of Sciences, 896(1), 30-47. doi:10.1111/j.1749-6632.1999.tb08103.x

Nasir, N., Khan, S., Nasir, S. (2017). Workplace stressors and job performance: The hypothesized mediating role of job satisfaction incase of higher educational sector of pakistan. International Journal of Engineering Sciences \& Research Technology, 6(2), 609-623.

Pearsall, M. J., Ellis, A. P. J., Stein, J. H. (2009). Coping with challenge and hindrance stressors in teams: Behavioral, cognitive, and affective outcomes. Organizational Behavior and Human Decision Processes, 109(1), 18-28. doi:10.1016/j.obhdp.2009.02.002

Podsakoff, N. P., LePine, J. A., LePine, M. A. (2007). Differential challenge stressor-hindrance stressor relationships with job attitudes, turnover intentions, turnover, and withdrawal behavior: A meta-analysis. Journal of Applied Psychology, 92(2), 438-454. doi:10.1037/0021-9010.92.2.438 
Rodell, J. B., Judge, T. A. (2009). Can "good" stressors spark "bad" behaviors? The mediating role of emotions in links of challenge and hindrance stressors with citizenship and counterproductive behaviors. Journal of Applied Psychology, 94(6), 1438-1451.

Schwabe, L., Wolf, O. T. (2010). Learning under stress impairs memory formation. Neurobiol Learn Mem, 93(2), 183-188. doi:10.1016/j.nlm.2009.09.009

Selye, H. (1982). History and present status of the stress concept. In L. Goldberger \& S. Breznitz (Eds.), Handbook of stress: Theoretical and clinical aspects (pp. 7-17). New York: Free Press.

Viswesvaran, C., Ones, D. S., Schmidt, F. L. (1996). Comparative analysis of the reliability of job performance ratings. Journal of Applied Psychology, 81(5), 557-574.

Vroom, V. H. (1964). Work and motivation. New York: Wiley.

Wallace, J. C., Edwards, B. D., Arnold, T., Frazier, M. L., Finch, D. M. (2009). Work stressors, role-based performance, and the moderating influence of organizational support. Journal of Applied Psychology, 94(1), 254-262. doi:10.1037/a0013090

Webster, J. R., Beehr, T. A., Christiansen, N. D. (2010). Toward a better understanding of the effects of hindrance and challenge stressors on work behavior. Journal of Vocational Behavior, 76(1), 68-77. doi:10.1016/j.jvb.2009.06.012

Webster, J. R., Beehr, T. A., Love, K. (2011). Extending the challenge-hindrance model of occupational stress: The role of appraisal. Journal of Vocational Behavior, 79(2), 505-516. doi:10.1016/j.jvb.2011.02.001.

Zhang, Y., LePine, J. A., Buckman, B. R., Wei, F. (2014). It's not fair ... or is it? The role of justice and leadership in explaining work stressor-job performance relationships. Academy of Management Journal, 57(3), 675-697. doi:10.5465/amj.2011.1110. 